\title{
Aplicação de óleo no controle de Zabrotes subfasciatus e na germinação de Phaseolus vulgaris ${ }^{1}$
}

\author{
Maiene de F. C. de Queiroga ${ }^{2}$, Josivanda P. Gomes ${ }^{2}$, Francisco de A. C. Almeida ${ }^{2}$, \\ Elvira B. Pessoa ${ }^{2}$ \& Niédja M. C. Alves ${ }^{2}$
}

\begin{abstract}
RESUMO
Propôs-se, com este trabalho, estudar a qualidade de sementes de feijão carioca (Phaseolus vulgaris L.) tratadas com óleos vegetais de mamona, soja e oiticica, durante cinco meses de armazenamento. Mediante os resultados obtidos concluiu-se que os óleos vegetais utilizados no tratamento das sementes de feijão Phaseolus foram eficientes na manutenção da viabilidade e no controle da infestação pelo inseto-praga de armazenamento Zabrotes subfasciatus, nos cinco meses de armazenamento, sendo o óleo de oiticica o que apresentou melhor média de germinação, frente às tratadas com óleo de mamona e soja. O óleo de oiticica também foi o mais eficiente no controle de $Z$. subfasciatus. Verificou-se, ainda, redução da eficiência dos óleos nas suas menores doses, sendo a dose de 4,5 mL para $500 \mathrm{~g}$ de sementes, a mais eficaz para todas as variáveis estudadas.
\end{abstract}

Palavras-chaves: controle de insetos-praga, armazenamento de sementes, óleo vegetal

\section{Oil aplication in the control of Zabrotes subfasciatus and in the germination of Phaseolus vulgaris}

\begin{abstract}
The purpose of this work was to study the quality of bean seeds (Phaseolus vulgaris L.) treated with vegetable oils of castor, soybean and 'oiticica' during five months of storage. From the obtained results it was concluded that vegetable oils used in the treatment of seeds of Phaseolus beans were effective in maintaining the viability and control of storage insect pest infestation Zabrotes subfasciatus during the five months of storage, and the 'oiticica' oil presented the best mean germination, compared to those treated with castor oil and soybeans. 'Oiticica' oil was also the most efficient in controlling Z. subfasciatus. Reduced efficiency of the oils was observed in the small doses and the dose of $4.5 \mathrm{~mL}$ for $500 \mathrm{~g}$ of seeds was the most effective for all variables.
\end{abstract}

Key words: control of insect pests, seed storage, vegetable oil 


\section{INTRODUÇÃO}

O feijoeiro (Phaseolus vulgaris L.) é não apenas importante cultura de subsistência mas também uma das principais fontes de proteínas na dieta humana, sobretudo para populações de baixa renda, especialmente na América Latina e África. No Brasil, o feijão é cultivado, sobremaneira, por pequenos e médios produtores, na sua maioria utilizando baixo nível tecnológico (Borém \& Carneiro, 2006), representando uma fonte significativa de renda e subsistência porém sua produtividade é considerada baixa devido a alguns fatores, dentre os quais se inclui o ataque por inúmeras pragas (Boiça Júnior et al., 2002) desde a emergência até o armazenamento, sendo o Zabrotes subfasciatus (Boheman, 1833) (Coleoptera, Bruchidae) a principal praga de feijão armazenado.

Em razão do seu potencial depreciativo, a espécie $Z$. subfasciatus constitui importante praga do feijão armazenado no Brasil, reduzindo o peso e a qualidade dos grãos e sementes, especialmente quanto à germinação das sementes. Esta espécie é considerada cosmopolita, ocorrendo em todas as regiões do globo terrestre em que se faz o armazenamento de feijões, desde que fatores climáticos não limitem seu ciclo de vida, além de apresentar distribuição ampla nas regiões quentes e tropicais da América Latina (Brito et al., 2006).

O inseto Z. subfasciatus ataca os cotilédones do feijão armazenado e, na fase larval, abre galerias, podendo destruílos completamente, ao que se soma a presença de ovos nos grãos, de orifícios de emergência dos adultos, de insetos mortos e de excrementos que afetam a qualidade do produto. Os grãos destinados à semeadura têm os embriões destruídos, ficando seriamente prejudicados (Gallo et al., 2002).

A utilização de plantas com atividade inseticida no controle de pragas no armazenamento se deve sobretudo ao surgimento da resistência dos insetos a inseticidas organossintéticos, à contaminação por eles causada à presença de resíduos químicos tóxicos nos alimentos e à intoxicação dos operários aplicadores de inseticida (Estrela et al., 2006).

Por outro lado, as plantas inseticidas são uma alternativa viável por ter baixo custo, ser de fácil preparação e facilmente encontradas. Elas têm sido muito utilizadas no controle de insetos durante o armazenamento de grãos de feijão, em países da América Latina, África e Ásia. Podem ser usadas como óleo, pós secos e extratos, com ação sobretudo de contato e fumigante. Podem causar repelência, alterar o crescimento, prolongar o desenvolvimento, impedir a muda, afetar a reprodução e ocasionar mortalidade (Almeida et al., 2009).

O uso de alguns óleos vegetais no tratamento de sementes tem sido eficiente no controle de carunchos, provocando redução na progênie e na emergência de adultos (Barbosa et al., 2002; Costa et al., 2004; Estrela et al., 2006; Coitinho et al., 2006).

Neste trabalho objetivou-se avaliar a infestação por $Z$. subfasciatus e a germinação de sementes de feijão carioca tratadas com óleos fixos de mamona, soja e oiticica, durante o armazenamento.

\section{Material E MÉTODOS}

O experimento foi realizado no Laboratório de PréProcessamento e Armazenamento de Produtos Agrícolas (LAPPA) da Unidade Acadêmica de Engenharia Agrícola (UAEA) do Centro de Tecnologia e Recursos Naturais (CTRN), da Universidade Federal de Campina Grande (UFCG) e no Laboratório de Entomologia do Centro de Ciências Agrárias de Areia, da Universidade Federal da Paraíba (UFPB).

As temperaturas e as umidades relativas do ar no período em que foi realizado o experimento foram obtidas na Estação Climatológica da Embrapa Algodão, Campina Grande, PB.

A criação de populações de $Z$. subfasciatus foi desenvolvida em laboratório (LAPPA), a partir de indivíduos coletados em feijão adquirido na feira livre de Campina Grande e identificados no laboratório de Entomologia do Centro de Ciências Agrárias de Areia (UFPB). A espécie acima citada foi mantida em BOD (modelo101/3) regulado a temperatura de $28 \pm 1^{\circ} \mathrm{C}$ e umidade relativa não controlada dentro deste.

Para multiplicação do inseto, os exemplares coletados foram colocados juntamente com grãos íntegros de feijão carioca, previamente expurgados, em recipiente de vidro com capacidade de $300 \mathrm{~mL}$ (15,25 cm de altura por 5,9 cm de diâmetro), revestidos por uma tela transparente com tecido de voil para permitir a ventilação em seu interior, os quais foram levados a uma estufa incubadora com temperatura de 28 e $95 \%$ de UR. Após a inoculação foi aguardado um período de 35 dias para cópula e postura; depois, os carunchos adultos foram retirados da massa de grãos com auxílio de uma peneira de quatro mesh, deixandose apenas os grãos mais as posturas no local até a emergência dos insetos adultos que foram utilizados nos experimentos.

Os óleos vegetais utilizados no controle da infestação do $Z$. subfasciatus e na manutenção da germinação das sementes de feijão carioca, foram escolhidos a partir de citações bibliográficas sobre seu emprego no controle de insetos-praga de sementes e grãos armazenados tomando-se, como controle, sementes tratadas com fosfina e sementes não tratadas.

O óleo de oiticica (Licania rigida) foi fornecido pela Resibras S.A. de Fortaleza, CE. e o de mamona (Ricinus communis L.) pela Aboissa Óleos Vegetais, SP, ambos extraídos por prensagem a frio, em filtro prensa e posteriormente degomado, desodorizado, clarificado e neutralizado. O óleo de soja (Glycine max Merril) foi obtido em supermercado, aleatoriamente.

Os óleos de mamona, soja e oiticica foram utilizados no tratamento das sementes de feijão carioca aplicados manualmente sobre a massa de sementes, na razão de $62,5 \mathrm{~mL}$ de óleo para cada 12,5 $\mathrm{kg}$ de sementes, nas doses de 0,5, 1,5, 2,5, 3,5 e 4,5 mL (D1, D2, D3, D4 e D5, respectivamente), para cada $500 \mathrm{~g}$ de sementes; em seguida, foram colocadas sobre folhas de jornal para secagem natural à sombra, por $24 \mathrm{~h}$, no LAPPA e, a seguir, acondicionadas em embalagens plásticas (politeraftalato de etileno), tendo sido inoculados, em cada embalagem, 30 insetos na fase adulta, de Z. subfasciatus com idade desconhecida, onde permaneceram armazenadas durante cinco meses, além de avaliadas mensalmente quanto à germinação e infestação pelo inseto. Os resultados obtidos foram expressos em porcentagem. 
Realizou-se o teste de germinação em laboratório utilizandose quatro repetições de 50 sementes colocadas em folhas de papel germitest, ou seja, duas na base e uma folha em cobertura, umedecidas em água destilada, na proporção de três vezes o peso do papel seco. Rolos foram confeccionados e acomodados em recipientes plásticos para evitar perda de umidade e, posteriormente, colocados para germinar a $25 \pm 1{ }^{\circ} \mathrm{C}$; para manter a umidade relativa em torno de $95 \pm 2 \%$, colocaram-se cubas com água na parte inferior da incubadora. As contagens foram realizadas nos quinto e nono dias após a semeadura, cujas avaliações foram feitas de acordo com as Regras para Análise de Sementes (Brasil, 2009).

A partir de $100 \mathrm{~g}$ da amostra foram contadas 100 sementes, dentre as quais se separaram as danificadas das íntegras. $\mathrm{O}$ cálculo da porcentagem de sementes danificadas foi feito em relação ao número total de sementes retiradas da amostra. Para expressar o percentual de infestação de Z. subfasciatus foi utilizada a Eq. 1, descrita por por Almeida et al. (2009).

$$
\mathrm{PI}=\frac{\mathrm{D}}{\mathrm{D}+\mathrm{I}} \times 100
$$

em que:

PI - porcentagem de infestação
D - número de sementes danificadas por Zabrotes subfasciatus
I - número de sementes íntegras

Os resultados foram analisados através do Programa Computacional Sisvar versão 5.3 (Ferreira, 2010), utilizando-se o delineamento inteiramente casualizado (DIC), dispostos em esquema fatorial $(3 \times 5 \times 6 \times 4)$ para a embalagem de PET, representado por: tratamento com óleos de mamona, soja e oiticica, doses dos óleos, períodos de armazenamento e número de repetições, respectivamente. As médias foram comparadas pelo teste de Tukey e, para os fatores quantitativos (dose e período), estudou-se regressão na análise de variância.

\section{RESULTADOS E DISCUSSÃO}

A análise de variância das porcentagens de germinação revelou efeito significativo para todos os fatores e suas interações, com exceção do fator óleo (Tabela 1).

Os resultados de germinação das sementes de feijão carioca tratadas com óleos vegetais de mamona, soja e oiticica acondicionadas em embalagens tipo PET, depois de 5 meses de armazenamento sob condições naturais de laboratório, ou seja, sem controle de temperatura e umidade relativa do ar, estão representados graficamente na Figura 1 para interação óleos x doses.

Pela Figura 1, a germinação das sementes de feijão aumentou com o aumento das doses de óleo de mamona e de oiticica (valores médios de 54,5 e 53,1\%), exceto para a dose $\mathrm{D}_{4}$, ocorrendo o contrário quando se utilizou o óleo de soja $(51,7 \%)$. Entretanto, não houve respostas da germinação aos tratamentos $\mathrm{D}_{2}, \mathrm{D}_{3}$ e $\mathrm{D}_{4}$, que apresentaram comportamento diferenciado nas doses $\mathrm{D}_{1}$ e $\mathrm{D}_{5}$, notando-se que na dose $\mathrm{D}_{1}$ as
Tabela 1. Resumo da análise de variância da germinação (\%) das sementes de feijão carioca (Phaseolus vulgaris L.) tratadas com óleos vegetais de mamona, soja e oiticica, após cinco meses de armazenamento em embalagem tipo PET

\begin{tabular}{lrc}
\hline \multirow{1}{*}{ FV } & GL & Quadrado médio \\
\cline { 3 - 3 } Óleo (O) & 2 & Germinação \\
Dose (D) & 4 & $183,76^{\text {ns }}$ \\
Período (P) & 4 & $930,57^{\star *}$ \\
O x D & 8 & $13264,37^{\star *}$ \\
O x P & 8 & $653,36^{\star *}$ \\
D x P & 16 & $415,01^{\star *}$ \\
O x D x P & 32 & $543,78^{\star *}$ \\
Resíduo & 225 & $339,34^{\star *}$ \\
\hline CV & & 167,91 \\
\hline
\end{tabular}

ns - Não significativo; ** - Significativo a p d" 0,01; FV - Fonte de variação; GL - Grau de liberdade

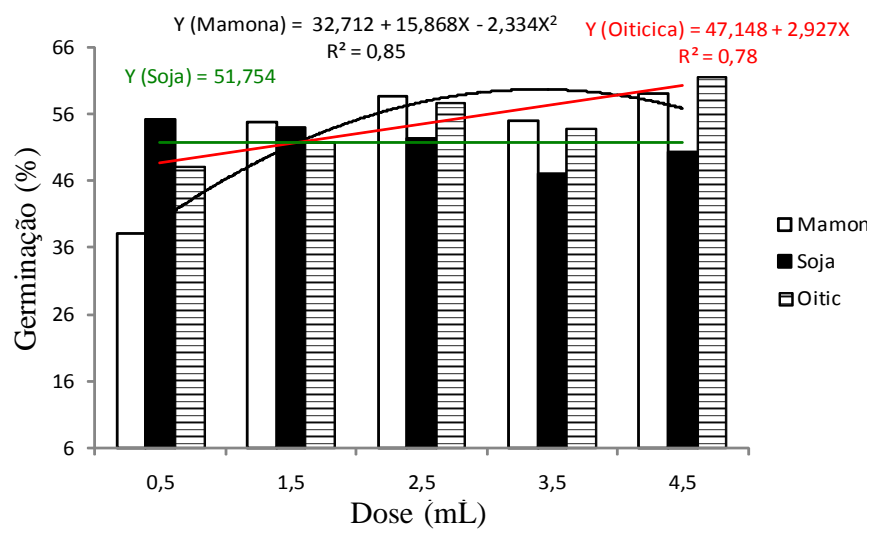

Figura 1. Desdobramento da interação óleos x doses para a germinação (\%) das sementes de feijão carioca (Phaseolus vulgaris L.) tratadas com diferentes doses, dentro de cada óleo vegetal

sementes tratadas com óleos de soja e oiticica exibiram maior germinação do que com óleo de mamona e, na dose $\mathrm{D}_{5}$, a menor germinação foi obtida com óleo de soja, que não diferiu da germinação com óleo de mamona e foi inferior às tratadas com óleo de oiticica.

As melhores respostas às doses mais elevadas dos óleos de mamona e oiticica são devidas, provavelmente, a uma aderência melhor dos compostos lipofílicos, os quais protegeram as sementes de ataque de insetos e infestação de parasitos, regulando as taxas metabólicas que causam deterioração e diminuição da germinação. Parente et al. (2003) afirmaram que o óleo de mamona é um dos óleos mais densos, apresentando alta resistência ao escoamento e forte viscosidade, características que se conjugam na formação de uma película envolvente e isoladora do contato direto da superfície em que é usado. Beltrão \& Oliveira (2007) enfatizaram que o óleo de oiticica, quando aquecido durante alguns minutos a $230{ }^{\circ} \mathrm{C}$, se torna permanentemente líquido e fornece, pela secagem, películas lisas e resistentes que envolvem as sementes, protegendo-as.

Observa-se ainda que para as doses dos óleos empregados no tratamento das sementes de feijão, os coeficientes da equação polinomial foram de $51,7 \%$ (soja), $78 \%$ (oiticica) e $85 \%$ 
(mamona), que se devem às doses de óleo usadas, isto é, a germinação das sementes responde à dose de óleo com que foram tratadas, assim como ao tipo de óleo e, também, que os óleos utilizados no tratamento foram eficientes na manutenção da germinação, durante o armazenamento.

Esses resultados demonstram a viabilidade da utilização de métodos simples, eficazes e de custo reduzido para conservar sementes de feijão em condição de pequena propriedade e que os óleos de mamona e oiticica utilizados no tratamento das sementes, na dose de 4,5 mL para $500 \mathrm{~g}$ de sementes, preservam sua qualidade durante o período de entressafra (cinco meses). A facilidade de obtenção desses óleos, seu fácil manejo, os custos reduzidos e a eficiência no controle de carunchos, são as principais vantagens desses tratamentos, além de não serem tóxicos, não favorecer ao desenvolvimento de população de insetos resistentes e não deixar resíduos tóxicos nos grãos que se destinam ao consumo.

Referidos resultados são importantes, especialmente porque o controle de insetos-praga de feijão armazenado é feito, predominantemente, por meio de produtos químicos que, além de agredirem o meio ambiente, têm trazido problemas à saúde humana (Pereira et al., 2008). Os autores ressaltam que a resistência dos insetos-praga aos inseticidas sintéticos exige o emprego de concentrações mais elevadas desses produtos no seu controle; desta forma, o uso de óleos vegetais e, aqui especificamente, os de mamona, soja e oiticica, no controle da qualidade das sementes de feijão carioca armazenadas, apresentam as vantagens de menor impacto ambiental e maior segurança para o homem, tanto para o aplicador quanto para o consumidor final.

Segundo Castro et al. (2010), diante da elevada demanda por inseticidas de baixo impacto ambiental, a utilização de derivados (pó, extrato e óleo essencial) de plantas se configura como alternativa promissora. No entanto, apesar de diversas espécies de plantas apresentarem resultados positivos em pesquisas, ainda há necessidade de muita investigação para solucionar alguns entraves à utilização desses produtos, tais como a fácil decomposição, a toxicidade a insetos benéficos e aos inimigos naturais das pragas, tal como definir a melhor maneira de prepará-los e conservá-los para que não percam suas propriedades ativas.

Os dados dos fatores quantitativos relativos ao desdobramento do óleo dentro de cada período foram submetidos à análise de regressão e, quando significativos, estudada a melhor equação para representá-los, em que no presente estudo a de primeira e a de segunda ordem os representam com $\mathrm{R}^{2}$ superior a $92 \%$ para todos os óleos estudados ao longo do armazenamento (Figura 2).

Pela Figura 2 observa-se que as sementes tratadas com os diferentes óleos revelaram comportamento similar durante o armazenamento, de vez que as maiores médias de germinação foram obtidas aos 30 dias de armazenagem $(76,7 \%)$ e nos demais períodos essas médias foram reduzidas continuamente, até o final do armazenamento. Para todos os óleos estudados ocorreu redução da porcentagem de germinação ao longo do armazenamento; as sementes tratadas com óleo de oiticica foram as que perderam mais rapidamente a germinação em $\mathrm{P}_{30}$ mas apresentaram maiores porcentagens de germinação durante

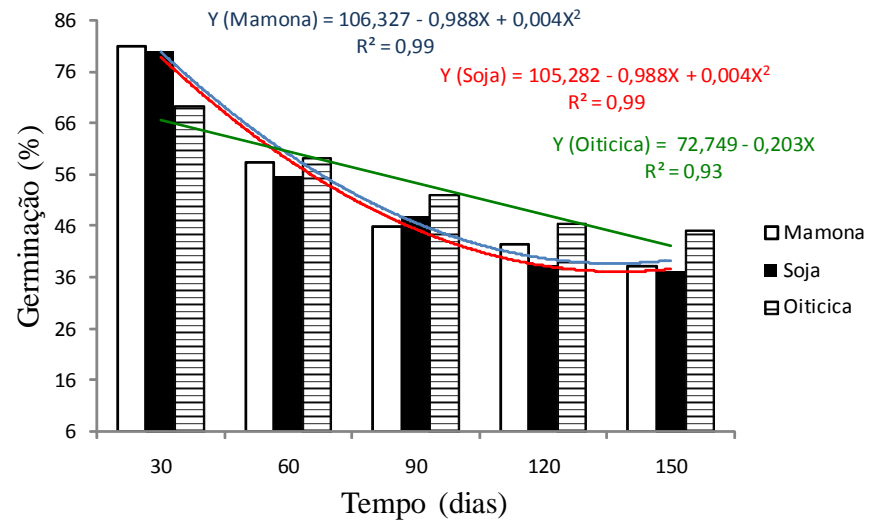

Figura 2. Desdobramento da interação óleo x período para a germinação (\%) das sementes de feijão carioca (Phaseolus vulgaris L.) tratadas com diferentes óleos, dentro de cada período de armazenamento

os 150 dias de estocagem; já nas sementes tratadas com óleo de soja a germinação foi mais afetada durante o armazenamento que nas sementes tratadas com os outros óleos. Logo, a diminuição no percentual de germinação se deveu ao período de armazenamento e não à interferências dos óleos empregados.

Bavaresco (2007) verificou que o controle e o óleo de soja não foram eficientes contra o caruncho-do-feijão, enquanto o óleo de nim e a areia apresentaram comportamento intermediário, reduzindo o aumento populacional e o dano do inseto em relação ao controle. Por outro lado, Almeida et al. (2005a), constataram que os extratos de Calopogonium caeruleum e Piper nigrum, na dose de 3 e $6 \mathrm{~mL}$ se mostraram eficientes com efeitos ovicidas sobre o Callosobruchus maculatus. De acordo com Azevedo et al. (2010), o óleo de nim foi mais eficiente sobre a mortalidade de insetos adultos de A. diaperinus aos 90 e 120 dias do armazenamento, nas concentrações de 3 e $4 \%$.

As equações de regressão linear e quadrática obtidas para representar o desdobramento da dose dentro de cada período de armazenamento (Figura 3), podem ser utilizadas para simular os intervalos dos dados obtidos experimentalmente com a confiança revelada pelos seus coeficientes de regressão $\left(\mathrm{R}^{2}\right)$.

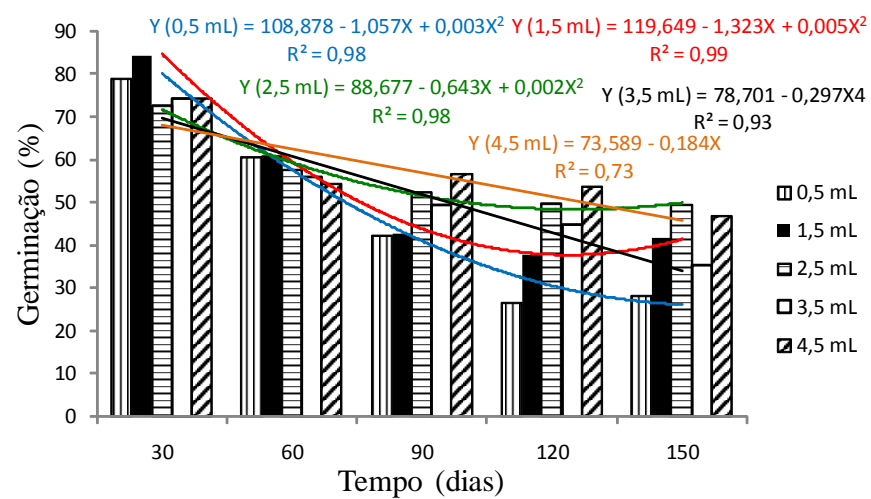

Figura 3. Desdobramento da interação dose x período para a germinação (\%) das sementes de feijão carioca (Phaseolus vulgaris L.) tratadas com diferentes doses, dentro de cada período de armazenamento 
Pela Figura 3 verifica-se a ocorrência de perda da germinação das sementes em todas as doses durante o armazenamento, exceto para as doses $\mathrm{D}_{5}$ aos 90 dias e $\mathrm{D}_{1}$ e $\mathrm{D}_{2}$ aos 150 dias de armazenagem. Constata-se, também, que a maior perda de germinação das sementes ocorreu em $\mathrm{D}_{1}(47,1 \%)$, seguida de $\mathrm{D}_{4}(51,9 \%)$ e $\mathrm{D}_{2}(53,5 \%)$ e a menor em $\mathrm{D}_{5}(56,9 \%)$.

De modo geral, as menores perdas de germinação aos $30 \mathrm{e}$ 60 dias foram aquelas tratadas nas doses $\mathrm{D}_{1}$ e $\mathrm{D}_{2}$ e, a partir deste período até os 150 dias de armazenamento, os maiores percentuais de germinação foram alcançados com as doses $\mathrm{D}_{3}$, $\mathrm{D}_{4}$ e $\mathrm{D}_{5}$ fato se deve, sem dúvida, à constituição dos óleos e sua interação com as sementes tratadas, uma vez que os melhores resultados de germinação (média) em doses mais elevadas dos óleos.

Almeida et al. (2009) afirmaram que o extrato de Pipernigrum foi eficiente em $56,2 \%$ na manutenção da germinação das sementes de feijão macassar armazenadas durante até 360 dias. Neste mesmo sentido, Medeiros et al. (2007) observaram que pós de folhas secas e verdes de nim não apresentaram efeito tóxico para as sementes de caupi em relação à primeira contagem de plântulas e porcentagem de germinação, exceto para a matéria seca das plântulas.

Almeida et al. (2009) determinaram a perda de viabilidade de duas variedades de Vigna ungüiculata, tratadas com extrato de Piper nigrum, acondicionadas e armazenadas em ambiente não controlado, durante 360 dias e detectaram que a viabilidade das sementes foi afetada pelos tratamentos e condições do armazenamento sendo que a variedade Emepa apresentou maior viabilidade e o extrato de $P$. nigrum revelou-se eficiente na manutenção da viabilidade dessas sementes.

Viegas et al. (2005) encontraram, avaliando alguns produtos sobre a qualidade fisiológica de sementes de amendoim, que os produtos à base de pó de alho e canela e do fungicida Captan favorecem a germinação e o vigor das sementes.

A análise de variância dos dados de infestação obtidos experimentalmente, revelou efeito bastante significativo para todos os fatores e suas interações (Tabela 2).

A infestação de sementes de feijão por Z. subfasciatus diminuiu com o aumento das doses de óleos de mamona, soja e oiticica; para a dose $\mathrm{D}_{1}$, as sementes tratadas com óleos de soja e oiticica apresentaram menor infestação de insetos e em

Tabela 2. Resumo da análise de variância da infestação (\%) nas sementes de feijão carioca (Phaseolus vulgaris L.) tratadas com óleos vegetais de mamona, soja e oiticica, após 5 meses de armazenamento embalagem tipo PET

\begin{tabular}{|c|c|c|}
\hline \multirow{2}{*}{ FV } & \multirow{2}{*}{ GL } & Quadrado médio \\
\hline & & Infestação \\
\hline Óleo (0) & 2 & 664,91 ** \\
\hline Dose (D) & 4 & $9614,95^{\star *}$ \\
\hline Período (P) & 4 & $4480,04 * *$ \\
\hline $0 \times D$ & 8 & $403,47 * *$ \\
\hline $0 \times P$ & 8 & $421,72^{* *}$ \\
\hline$D \times P$ & 16 & $2220,10^{* *}$ \\
\hline $0 \times D \times P$ & 32 & 294,10 ** \\
\hline Resíduo & 225 & 2,99 \\
\hline CV & & 22,97 \\
\hline
\end{tabular}

** - Significativo a 1\% de probabilidade; FV - Fonte de variação; GL - Grau de liberdade
$\mathrm{D}_{2}$ o melhor controle se deu para as sementes tratadas com óleo de oiticica. A partir da dose $\mathrm{D}_{3}$ ocorreu diminuição drástica na infestação de sementes de feijão para os tratamentos com os diferentes óleos, com valores próximos de zero. Os valores médios da infestação nas sementes tratadas com os óleos testados foram muito baixos durante todo o período de armazenamento (cinco meses), em que a média geral de infestação variou de apenas 4,9 a 9,4\%, fato que se deve, sem dúvida, à eficiência dos óleos em proteger a área superficial das sementes, formando uma barreira física que as reveste e impede o inseto-praga $Z$. subfasciatus, de completar seu ciclo biológico, uma vez que a fêmea deposita os ovos sobre o tegumento das sementes de feijão, hospedeiro extremamente necessário para a alimentação e proteção das larvas deste inseto, que se desenvolvem no interior da semente.

Resultados semelhantes obtiveram Brito et al. (2006) ao verificar que o processo de fumigação com óleos essenciais de plantas do gênero Eucalyptus se mostrou eficiente no controle de Z. subfasciatus e Callosobruchus maculatus; as porcentagens de ovos viáveis e as de adultos emergidos das duas espécies de carunchos, sofreram redução com a aplicação dos três óleos essenciais e os óleos de Eucalyptus staigeriana e E. citriodora tiveram as menores porcentagens de ovos viáveis e insetos emergidos para os dois carunchos.

De forma geral, o maior percentual de infestação se deu no tratamento com a dose $\mathrm{D}_{1}(0,5 \mathrm{~mL})$ para todas as sementes armazenadas tendo o óleo de mamona se revelado superior aos demais óleos. A menor incidência de insetos promovida pelas doses $\mathrm{D}_{3}$ a $\mathrm{D}_{5}$ foi detectada para todos os óleos estudados, o que se deve, provavelmente, ao método de aplicação de forma direta sobre as sementes, que reduziu por completo o número de ovos viáveis e de insetos emergidos, de acordo com o aumento das doses, pois os óleos têm, em comum, a propriedade física de forte aderência ao tegumento das sementes e constituem uma barreira de proteção contra a oviposição e/ou desenvolvimento larval do inseto que, por sua vez, não consegue completar o ciclo biológico. Esses resultados coadunam com os encontrados por Almeida et al. (2005a) que, trabalhando com oito extratos vegetais e três métodos de aplicação sobre Callosobruchus maculatus na fase adulta e imatura (ovo), verificaram que a mortalidade dos insetos está relacionada com o tipo de extrato, com os métodos de aplicação e com a dosagem aplicada, em que a aplicação dos extratos diretamente sobre a massa de sementes, foi o método mais eficiente no controle ao $C$. maculatus e os extratos de Calopogonium caeruleum e Piper nigrum, nas doses de três e seis $\mathrm{mL}$, se mostraram eficientes, com efeitos ovicidas.

Os óleos testados foram eficazes no controle de $Z$. subfasciatus, com efeito ovicida/larvicida expressivo, reduzindo a emergência de adultos, sendo o óleo de oiticica o que apresentou a melhor resposta neste sentido (Figura 4).

Analisando a Figura 4, verifica-se que as sementes tratadas com os óleos de mamona, soja e oiticica, foram eficientes no controle de insetos-praga até os 60 dias de armazenamento e a porcentagem de infestação foi de 3,4, 1,15 e 0,25\%, respectivamente. Após este período ocorreu maior infestação e, de forma crescente aos 90 e 120 dias de estocagem das sementes, diminuindo no último período (150 dias). 


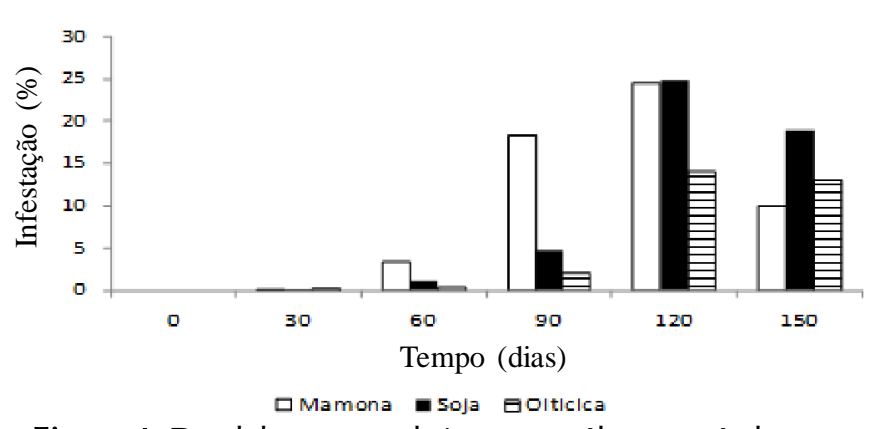

Figura 4. Desdobramento da interação óleo x período para a infestação (\%) nas sementes de feijão carioca tratadas com diferentes óleos, dentro de cada período de armazenamento

Avaliando o grau de infestação dentro de cada período de armazenamento notou-se que o óleo de oiticica promoveu maior controle de insetos-praga até os 120 dias em que as sementes ficaram estocadas, em confronto com as sementes tratadas com óleo de mamona que exerceram comportamento similar ao das sementes com óleo de soja, verificando-se maior ataque de insetos neste período de armazenamento, em que os óleos de mamona e de soja exerceram menor influência sobre o controle de pragas em relação ao óleo de oiticica.

Verificou-se, para as sementes tratadas com óleo de mamona ao longo do período da armazenagem, aumento do percentual de infestação à medida em o tempo avança, exceto em $\mathrm{P}_{150} \mathrm{e}$ que em $\mathrm{P}_{120}$ a infestação foi maior que em $\mathrm{P}_{90}, \mathrm{P}_{60}$ e $\mathrm{P}_{30}$, nesta ordem: $\left(\mathrm{P}_{120}>\mathrm{P}_{90}>\mathrm{P}_{60}>\mathrm{P}_{30}\right)$. Por outro lado, as sementes menos infestadas até 120 dias, foram as tratadas com óleo de oiticica que, em $\mathrm{P}_{120}(13,95 \%)$ e $\mathrm{P}_{90}(2,00 \%)$, resistiram com maior eficiência à infestação frente às sementes com óleo de mamona $(24,55 \%)$ em $\mathrm{P}_{120}$ e $(18,35 \%)$ em $\mathrm{P}_{90}$, e de soja $(24,85 \%)$ e $(4,75 \%)$ para $\mathrm{P}_{120}$ e $\mathrm{P}_{90}$, respectivamente (Figura 4).

Almeida et al. (2005b) estudaram, durante seis meses, o armazenamento de feijão Vigna unguiculata tratado com mamona para prevenção do Callosobruchus maculatus e verificaram que os tratamentos $\mathrm{P}_{1}$ (grãos de feijão $+5 \%$ de sementes de mamona triturada) e $\mathrm{P}_{2}$ (grãos $+10 \%$ de sementes trituradas) foram eficientes no combate ao Callosobruchus maculatus, durante os 180 dias de armazenamento.

Os dados dos fatores quantitativos relativos ao desdobramento das doses dentro de cada período foram submetidos à análise de regressão, sendo mais bem representados graficamente na Figura 5.

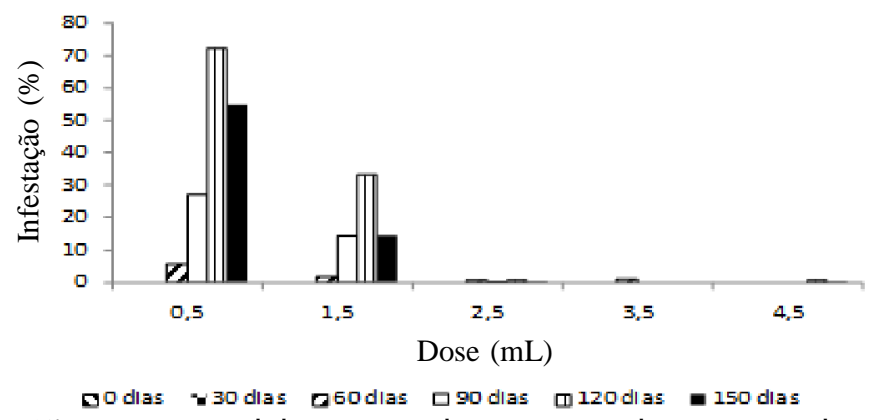

Figura 5. Desdobramento da interação dose x período para a infestação (\%) nas sementes de feijão carioca (Phaseolus vulgaris L.) tratadas com diferentes doses, dentro de cada período de armazenamento
Pela Figura 5 observou-se que as doses $\mathrm{D}_{3}(2,5 \mathrm{~mL}), \mathrm{D}_{4}(3,5$ $\mathrm{mL})$ e $\mathrm{D}_{5}(4,5 \mathrm{~mL})$ controlaram a infestação com maior eficiência em todos os períodos, em comparação com as doses $\mathrm{D}_{1}(0,5$ $\mathrm{mL})$ e $\mathrm{D}_{2}(1,5 \mathrm{~mL})$, sendo que a dose $\mathrm{D}_{1}$ foi a menos eficiente no controle da infestação, durante a armazenagem.

Entre os períodos notou-se crescimento uniforme do percentual de infestação até os 120 dias para as doses $\mathrm{D}_{1}$ e $\mathrm{D}_{2}$; em contrapartida, as doses $\mathrm{D}_{3}$ a $\mathrm{D}_{5}$ mantiveram sua eficiência até os 150 dias de armazenamento. Knaak \& Fiuza (2010) afirmaram que o efeito de óleos adicionados às sementes é devido ao bloqueio do oxigênio para a respiração dos insetos e ao efeito inseticida de alguns de seus componentes, principalmente dos triglicerídeos.

Barbosa et al. (2002) verificaram que os óleos de nim e de soja misturados aos grãos de feijão, foram eficientes no controle de Z. subfasciatus durante o período de até 150 dias de armazenagem, conferindo alto nível de proteção aos danos do inseto.

\section{ConClusÕES}

1. As maiores doses dos óleos vegetais utilizados no tratamento das sementes de feijão Phaseolus, conferiram melhor resposta para a germinação, vigor e teor de umidade das sementes, com destaque para $\mathrm{D}_{3}(2,5 \mathrm{~mL})$ e $\mathrm{D}_{5}(4,5 \mathrm{~mL})$.

2. Os óleos vegetais empregados no tratamento de sementes de feijão foram eficientes no controle de Zabrotes subfasciatus, durante todo o período de armazenamento, sendo o óleo de oiticica o que promoveu maior controle até os 120 dias de estocagem.

3. A infestação nas sementes de feijão pelo inseto Zabrotes subfasciatus diminuiu com o aumento das doses dos óleos vegetais testados.

4. O óleo de oiticica e o de mamona na dose $\mathrm{D}_{5}(4,5 \mathrm{~mL})$ controlaram o Zabrotes subfasciatus, em $100 \%$.

\section{LITERATURA CITADA}

Almeida, F. de A. C.; Almeida, S. A. de; Santos, N. R. dos; Gomes, J. P.; Araújo, M. E. R. Efeitos de extratos alcoólicos de plantas sobre o caruncho do feijão vigna (Callosobruchus maculatus). Revista Brasileira de Engenharia Agrícola e Ambiental, v.9, p.585-590, 2005a.

Almeida, F. de A. C.; Cavalcanti, M. de F. B. S.; Santos, J. F. dos; Gomes, J. P.; Barros Neto, J. J. S. Viabilidade de sementes de feijão macassar tratadas com extrato vegetal e acondicionadas em dois tipos de embalagens. Acta Scientiarum Agronomy, v.31, p.345-351, 2009.

Almeida, I. P.; Duarte, M. E. M.; Cavalcanti-Mata, M. E. R. M.; Freire, R. M. M.; Guedes, M. A. Armazenamento de feijão macassar tratado com mamona: estudo da prevenção do Callosobruchus maculatus e das alterações nutricionais do grão. Revista Brasileira de Produtos Agroindustriais, v.7, p.133-140, 2005b. 
Azevedo, A. I. B. de; Lira, A. da S.; Cunha, L. C. da; Almeida, F. de A. C.; Almeida, R. P. de. Bioatividade do óleo de nim sobre Alphitobius diaperinus (Coleoptera: Tenebrionidae) em sementes de amendoim. Revista Brasileira de Engenharia Agrícola e Ambiental, v.14, p.309-313, 2010.

Barbosa, F. R.; Yokoyama, M.; Pereira, P. A. A.; Zimmermann, F. J. P. Controle do caruncho-do-feijoeiro Zabrotes subfasciatus com óleos vegetais, munha, materiais inertes e malathion. Pesquisa Agropecuária Brasileira, v.37, p.12131218, 2002.

Bavaresco, A. Avaliação de tratamentos alternativos para o controle do Acanthoscelides obtectus (Say) (Coleoptera: Bruchidae). Revista de Ciências Agroveterinárias, v.6, p.125133, 2007.

Beltrão, N. E. de M.; Oliveira, M. I. P. de. Oleaginosas potenciais do Nordeste para a produção de biodiesel, por Napoleão Esberard de Macêdo Beltrão. Campina Grande: Embrapa Algodão 2007. 53p. Documentos, 177

Boiça Júnior, A. L.; Botelho, A. C. G.; Toscano, L. C. Comportamento de genótipos de feijoeiro ao ataque de Zabrotes subfasciatus (Boheman, 1833) (Coleoptera: bruchidae) em condições de laboratório. Revista Arquivos do Instituto Biológico, v.69, p.51-55, 2002.

Borém, A.; Carneiro, S. E J. A cultura do feijão. In: Feijão. 2.ed. Cap. 3, Viçosa: UFV, 2006. 13-18p.

Brasil. Ministério da Agricultura e Reforma Agrária. Secretaria Nacional de Defesa Agropecuária. Regras para Análise de sementes. Brasília, 2009. 399p.

Brito, J. P.; Baptistussi, R. C.; Funichello, M.; Oliveira, J. E. M.; Bortoli, S. A. de. Efecto de aceites esenciales de Eucalyptus ssp. sobre Zabrotes subfasciatus (Boh., 1833) (Coleoptera: Bruchidae) y Callosobruchus maculatus (Fabr., 1775) (Coleoptera: Bruchidae) en dos especies del frijoles. Boletín de Sanidad Vegetal Plagas, v.32, p.573-580, 2006.

Castro, M. de J. P. de; Silva, P. H. S. da; Santos, J. R.; Silva, J. A. L. da. Efeito de pós vegetais sobrea oviposição de Callosobruchus maculatus (Fabr.) (Coleoptera: Bruchidae) em feijão-caupi. BioAssay, v.5, p.1-4, 2010.
Coitinho, R. L. B. C.; Oliveira, J. V.; Gondim Júnior, M. G. C.; Câmara, C. A. G. Efeito residual de inseticidas naturais no controle de Sitophilus zeamais Mots em milho armazenado. Revista Caatinga, v.19, p.183-191, 2006.

Costa, E. L. N.; Silva, R. F. P.; Fiuza, L. M. Efeitos, aplicações e limitações de extratos de plantas inseticidas. Acta Biologica Leopoldensia, v.26, p.173-185, 2004.

Estrela, J. L. V.; Fazolin, M.; Catani, V.; Alécio, M. R.; Lima, M. S. Toxicidade de óleos essenciais de Piper aduncum e Piper hispidinervum em Sitophilus zeamais. Pesquisa Agropecuária Brasileira, v.41, p.217-222, 2006.

Ferreira, D. F. Programa computacional Sisvar - UFLA, versão 5.3, 2010 .

Gallo, D.; Nakano, O.; Silveira Neto, S.; Carvalho, R. P. L.; Batista, G. C.; Berti Filho, E.; Parra, J. R. P.; Zucchi, R. A.; Alves, S. B.; Vendramim, J. D.; Marchini, L. C.; Lopes, J. R. S.; Omotto, C. Entomologia agrícola. Piracicaba: FEALQ, 2002. 920p.

Knaak, N.; Fiuza, L. M. Potencial dos óleos essenciais de plantas no controle de insetos e microrganismos. Neotropical Biology and Conservation, v.5, p.120-132, 2010.

Medeiros, D. C.; Andrade Neto, R. C.; Figueira, L. K.; Nery, D. K. P.; Maracujá, P. B. Pó de folhas secas e verdes de nim sobre a qualidade das sementes de feijão caupi. Revista Caatinga, v.20, p.94-99, 2007.

Parente, E. J. de S.; Santos Júnior, J. N.; Bastos, J. A.; Parente Júnior, E. J. de S. Biodiesel: Uma aventura tecnológica num país engraçado. Fortaleza: Tecbio, 2003. 66p.

Pereira, A. C. R. L.; Oliveira, J. V. de; Gondim Júnior, M. G. C.; Câmara, C. A. G. da. Atividade inseticida de óleos essenciais e fixos sobre Callosobruchus maculatus (Fabr., 1775) (Coleoptera: Bruchidae) em grãos de caupi [Vigna unguiculata (L.) Walp.]. Ciência e Agrotecnologia, v.32, p.717-724, 2008.

Viegas, E. C.; Nascimento, F. G.; Meyrelles, B. G.; Rosseto, C. A. V. Qualidade fisiológica de sementes armazenadas de amendoim influenciadas pelos produtos sintéticos e de origem vegetal. Revista Brasileira de Plantas Medicinais, v.7, p.79-85, 2005. 